\title{
Males as Partners in Family Planning Service Uptake in Ghana: A Descriptive Cross-Sectional Survey
}

\author{
Seth Christopher Yaw Appiah1,2*, Francis Adjei Osei ${ }^{3}$, Nicholas Karikari Mensah ${ }^{3}$, \\ Patrick Lebene Adonoo", Abdul Ganiu Tanko5, Phans Oduro Sarpong6 \\ ${ }^{1}$ Department of Sociology and Social Work, Kwame Nkrumah University of Science Technology, Kumasi, Ghana \\ ${ }^{2}$ Ludwig-Maximilians Universitate, LMU-Centre for International Health-University of Munich, Munchen, Germany \\ ${ }^{3}$ Public Health Unit, Komfo Anokye Teaching Hospital, Kumasi, Ghana \\ ${ }^{4}$ School of Government, Sun Yat-Sen University of Guangzhou, Guangzhou, China \\ ${ }^{5}$ Department of Planning, Kwame Nkrumah University Science Technology, Kumasi, Ghana \\ ${ }^{6}$ Research and Development Unit, Komfo Anokye Teaching Hospital, Kumasi, Ghana \\ Email: *sychrist207@gmail.com
}

How to cite this paper: Appiah, S.C.Y., Osei, F.A., Mensah, N.K., Adonoo, P.L., Tanko, A.G. and Sarpong, P.O. (2019) Males as Partners in Family Planning Service Uptake in Ghana: A Descriptive Cross-Sectional Survey. Health, 11, 1043-1054.

https://doi.org/10.4236/health.2019.118082

Received: February 13, 2019

Accepted: August 13, 2019

Published: August 16, 2019

Copyright (C) 2019 by author(s) and Scientific Research Publishing Inc. This work is licensed under the Creative Commons Attribution International License (CC BY 4.0).

http://creativecommons.org/licenses/by/4.0/

\begin{abstract}
Background: Family planning is an efficient and effective intervention that results in quick benefits for the whole family socio-economically. Differences exist in the rate of contraceptive use between male and female and male involvement of service uptake in Ghana. The objective of this study was to explore male direct involvement and or support to their partners in family planning service uptake. Methods: The study used a descriptive cross-sectional survey to sample 384 men of reproductive age (18 - 45 year) using cluster sampling to enlist participants from within the Suame Magazine light Industrial area in the Ashanti Region of Ghana. Data was analyzed descriptively using SPSS version 16. Results: Men showed very high knowledge (90\%) about what constitutes Family Planning, with moderate level of involvement both active and passive involvement (56\%) though only a few (38.9\%) were presently adopting or using modern contraceptive. The study rather found only $14 \%(55)$ males were willing to be solely responsible and actively involved in Family Planning service. Family Planning services did not adequately meet the needs of men with the services centers remaining unavailable in the study area. Conclusion: The extent of male involvement in family planning programmes is marginally above average. Males showed appreciable knowledge of family planning options though misconceptions continued to exist. A more couple-oriented approach to family planning is needed including recruiting males as family planning providers, offering more family planning counseling for couples, and promoting female-oriented methods with men and vice versa.
\end{abstract}




\section{Keywords}

Family Planning, Information Sharing, Attitude, Knowledge, Contraceptives, Utilization, Ghana

\section{Background}

There has always been the erroneous impression globally and particularly in Ghana, that men generally are not interested in Family Planning options. These perpetuated notions have continued to affect the success of Family Planning interventions. Men are at the centre of all that happens in African societies hence relegating them to the background on such a crucial issue as family planning is found to face serious challenges. Strategies to get men interested in family planning are only of recent development and family planning and reproductive health organisations are in the process of developing programs that will encourage male's participation in all such activities to relieve women of all the burden [1].

There is the need to focus on the design, integrating success lessons learned to promote men's reproductive health seeking behaviour and their active engagement in responsible and sexual and reproductive health matters [2] [3]. In spite of the strides made in the direction of involving men in Family Planning programmes, survey results suggest the uptake among women is still ahead of that of men. A cursory look at men participating in Family Planning shows that there exist cultural and programmatic barriers that act as a hindrance in men's participation in family planning programmers.

The attitude of males is a crucial factor to consider in terms of using modern contraceptive methods [4] and engaging them in Family Planning service uptake. Studies indicate that men are more likely to have heard about at least one form of contraceptive method most often condom than women. However, men are almost not aware of Female contraceptive methods [5]. Studies abound in other places in the world which indicate that the use and sustenance of family planning by women whose male counterpart supports them are a clear indication of continuous use of Family Planning [6]. In Chad and Pakistan, about three quarters of all married men had heard of at least one contraceptive method with much more likelihood that few men had heard of a modern Family Planning than a traditional method of contraceptive [7].

In sub-Saharan Africa, studies from 25 countries involved showed that 23 countries had more of their married men as having less awareness of female contraceptive methods including oral contraceptives, Intra Uterine Devices (IUD's) and injectable [8] than single men. This calls for greater levels of Family Planning education to engineering the level of awareness and knowledge about contraceptive methods for men. This is anticipated to be done through Information, Education and Communication (IEC) campaigns. However the bigger issue is moving beyond the rhetoric's of increase in knowledge to practical change in 
attitude and concrete actions [9].

A critical issue is about how to fashion out strategies to address men's needs through various service delivery efforts [1]. However, Family Planning landscape in terms of male participation does not appear changing as very low levels of involvement are kept being reported. This is more problematic when over thirty decades ago the findings remain the same. In 1984, while few studies had been conducted on the Sub region on Family Planning, a reproductive health survey showed that 42 percent of all married women opined that it was their husband's duty deciding whether the wife should adopt Family Planning methods. This view has remained unchanged or marginally altered in many Sub Saharan African countries. The idea that men are the final authorities in deciding on the number of children a family will have remained unchanged in many settings with few variations if in the twenty-first century across many African states [10].

In Ghana, studies by Wiafe (2015) established only $34.5 \%$ of males being involved in Family practice with education and an average knowledge of Family planning showing significant association with male involvement [11]. There have been marginal improvements in contraceptive prevalence to $21 \%$ according to the 2014 Ghana Demographic Health Survey report [12]. This paper seeks to examine the attitude of men of reproductive age towards the use of Family planning in general and particularly modern contraceptive use in Ghana.

\section{Methods}

\section{Study setting}

The Suame Magazine industrial area of Kumasi is a perfect example of an amalgam of small and medium scale industrial enterprises. It is an area where a large and growing number of people have created their own jobs in the informal sector. The sector covers a wide range of activities meeting local demands for a wide range of goods and service. The economy of Suame Magazine is dominated by sole proprietorship, cottage industries, apprentices and self-employed artisans which is chiefly male dominated.

\section{Study design and sampling and data collection}

The study adopted the descriptive cross-sectional approach with sampling population of 384 males. Inclusive criterion was set for males with ages falling within 18 - 45 years. Also, family planning providers from both the government and private sector were considered in this study. Simple random and purposive selection of men who met the inclusion criteria was done. This provided more and accurate information on the subject than men who were seen not to be of marriageable age. To avoid biased representation, the researchers used the quota sampling method to allocate equal number of respondents from each unit, that is, 77 respondents for each of the five suburbs selected for the study which were Shell area, Post office, Maakro, Cemetery area and Osborn junction area. The population of the Magazine industrial area as is estimated to be over 200,000 [13] [14]. Using the singe proportion formula for sample size estimation, the 
proportion of the population possessing the outcome attribute, that is male involvement was taken as $50 \%(0.5)$, with confidence interval was taken as \pm 1.96 at $95 \%$. The sample size was calculated to be 384 and this was the final recruit from the five clusters with Osborb area recruiting 76 participants.

An interviewer administered questionnaire designed and translated into local Asante Twi (dominant language of the majority of the population) was adopted. Males who met the inclusion criteria were recruited from within the divided clusters using simple random sampling procedure to allow for inclusion of all eligible participants. Those who declined participation were excused and moved on to other eligible men. This process continued until the allocated sample size from within each cluster was achieved. Male involvement in Family Planning was operationalised to mean whether male had personally used either modern contraceptive method or traditional method, ever accessed Family Planning clinics and or had supported the partner in using or as accessing Family Planning service or use any modern or traditional Family Planning option. This was measured on a binary response of Yes and No.

\section{Analysis}

The study results were analysed descriptively. This was done with the aid of the SPSS version 16. Data was collected from both primary and secondary sources. Tables and charts were used to ascribe quantitative value to qualitative data to make them amenable to statistical analysis. The responses and findings were converted to percentage scores to serve as units of measurement of results and findings of the study. This study is in compliance with the requirements of the Ethical clearance committee of the Kwame Nkrumah University of Science and Technology. Informed consent was sought from the participants. Additionally, the data collected did not contain information (names, addresses or identification numbers) that could easily make study participants identifiable. Confidentiality requirements were adhered to.

\section{Results}

\section{Background of participants}

Many of the participants 102 (26.5\%) were aged between 31 and 35. The results show $24(6.2 \%)$ of males had never had any formal education, 89 (23.2\%) had completed formal education or schooled up to the primary level. At least one out of every 10 male had completed tertiary education. Majority of males at the Suame magazine light industrial areas were married. There were 216 (56.3\%) married men with a third (31.5\%) being single. $18(4.6 \%)$ of the participants were divorced while $12(3.1 \%)$ remained separately (see Table 1 ).

Male Knowledge, involvement in Family planning and contraceptive usage

Knowledge on family was appreciably high. The study found 346 (90\%) of males to have had information about family planning. More than half (56.2\%) were involved in or approved of the need for males to get involve in family. 
There were 149 (38.9\%) males who were currently using at least one form of contraceptive methods though almost two thirds 235 (61.9\%) of males have never used any contraceptive method of a kind together with their partners. Males cited limited Family Planning options for men, unreliableness of condom use and the uncomfortableness with vasectomy being the only known male contraceptive method they are aware of apart from condom.

Table 1. Distribution of Socio-demographic background of participants.

\begin{tabular}{|c|c|c|}
\hline Variable & Frequency $(\mathrm{N}=384)$ & Percentage (\%) \\
\hline \multicolumn{3}{|l|}{ Age category in year } \\
\hline - $18-25$ & 77 & 20.0 \\
\hline - $25-30$ & 85 & 22.2 \\
\hline - $32-35$ & 102 & 26.5 \\
\hline - $36-40$ & 76 & 19.8 \\
\hline - $41-45$ & 44 & 11.5 \\
\hline \multicolumn{3}{|c|}{ Educational background of respondents } \\
\hline - Primary & 89 & 23.2 \\
\hline - Middle/JSS & 164 & 42.7 \\
\hline - Secondary & 68 & 17.7 \\
\hline - Tertiary & 39 & 10.2 \\
\hline - None & 24 & 6.2 \\
\hline \multicolumn{3}{|l|}{ Marital status } \\
\hline - Married & 216 & 56.3 \\
\hline - Single & 121 & 31.5 \\
\hline - Separated & 12 & 3.1 \\
\hline - Widowed & 17 & 4.4 \\
\hline - Divorced & 18 & 4.7 \\
\hline \multicolumn{3}{|l|}{ Religious background } \\
\hline - Christian & 302 & 78 \\
\hline - Traditionalist & 16 & 4.16 \\
\hline - Muslim & 48 & 12.5 \\
\hline - Others & 20 & 5.2 \\
\hline \multicolumn{3}{|l|}{ Background of Christian } \\
\hline - Catholic & 51 & 16.7 \\
\hline - Methodist & 61 & 20.1 \\
\hline - Presbyterian & 37 & 12.2 \\
\hline - Anglican & 23 & 7.6 \\
\hline - Pentecostal & 102 & 33.8 \\
\hline - Others & 28 & 9.2 \\
\hline \multicolumn{3}{|l|}{ Occupational Background } \\
\hline - Welders & 74 & 19.4 \\
\hline - Artist & 49 & 12.7 \\
\hline - Fitting & 98 & 25.5 \\
\hline - Other & 163 & 42.4 \\
\hline
\end{tabular}


There were $72.9 \%$ of males who knew about spacing birth while $27.1 \%$ understood family planning as using contraceptive only. However the combination of the two was not identified as a simultaneous means of Family Planning practice. Among 257 (66.9\%) of males family planning was an important practice in principle. About half 178 (46.3\%) of males had never visited any family planning centre in their life whether to uptake service or support a partner to see service. In the past two years a total of 169 (44\%) had ever visited any Family Planning centre. According to 178 (46.3\%) of the participants, both partners (couple) should practice family planning. A little over a third 136 (35.4\%) of the males opined that married women should practice family planning while a few number of males 15 (3.9\%) felt unmarried youth in their opinion should practice family planning.

Though some males were willing and had been involved in Family Planning practice passively (supporting their partners), in terms of active involvement (directly taking action) in family planning practice, only 14.3\% (55) admitted their willingness to be actively responsible and directly involved in the practice of family planning. Condoms 101 (26.3\%) were the main contraceptive family planning method partners ever patronized followed by periodic abstinence (17.3\%). Vasectomy as a contraceptive method recorded no response from males at the study area. Radio was identified as the chief source of family planning education representing 269 (70\%) of the responses from participants. Television provided family planning education for 61 (15.7\%) males (Table 2).

Table 2. Family planning knowledge, information sources and male involvement.

\begin{tabular}{lcc}
\hline \multicolumn{1}{c}{ Variable } & F (n = 384) & Percentage (\%) \\
\hline Source of Family Planning Information & & \\
- Radio & 269 & 70.0 \\
- Television & 67 & 17.4 \\
- Clinic and Hospital & 30 & 7.8 \\
- Others & 18 & 4.8 \\
Knowledge on Family Planning & & \\
- Yes & 346 & 90.1 \\
- No & 38 & 9.9 \\
Male involvement in Family Planning & & \\
- Involved & 216 & 56.3 \\
- Not involved & 168 & 43.7 \\
Current use of contraceptive & & \\
- Yes & 149 & 38.9 \\
- No & 235 & 61.1 \\
- Vamily Planning method ever used by male & & \\
- Male condoms & 101 & 26.3 \\
- Withdrawal & 38 & 9.9 \\
Periodic Abstinence & 45 & 11.8 \\
\hline
\end{tabular}




\section{Continued}

Men understanding of what family Planning is

- Spacing of birth only

- Using of contraceptives only

- Both contraceptive and birth spacing

Ever Visited Family Planning centre to seek service

- Never

46.3

- In the past six months

- Six months to a year

- One and half years

- More than 2 years

Spouse/Partner to be responsible for Family Planning practice

- Male /husband only

- Female/wife only

- Both partners/couple

Discussion on the number of children to have and responsibility towards practice of Family Planning

According to the results, nearly two third 240 (62.5\%) of males shared the view that the number of children to have was their prerogative to decide since they were the heads of the family. Less than a third (110) $28.6 \%$ of males admitted the need to discuss family size with their partners. Only $22(5.7 \%)$ of males saw the need to allow their partners decide on the size of their families. Only 12 (3.1\%) affirmed the need to allow the in-laws of partner to decide in matters of family size (Figure 1).

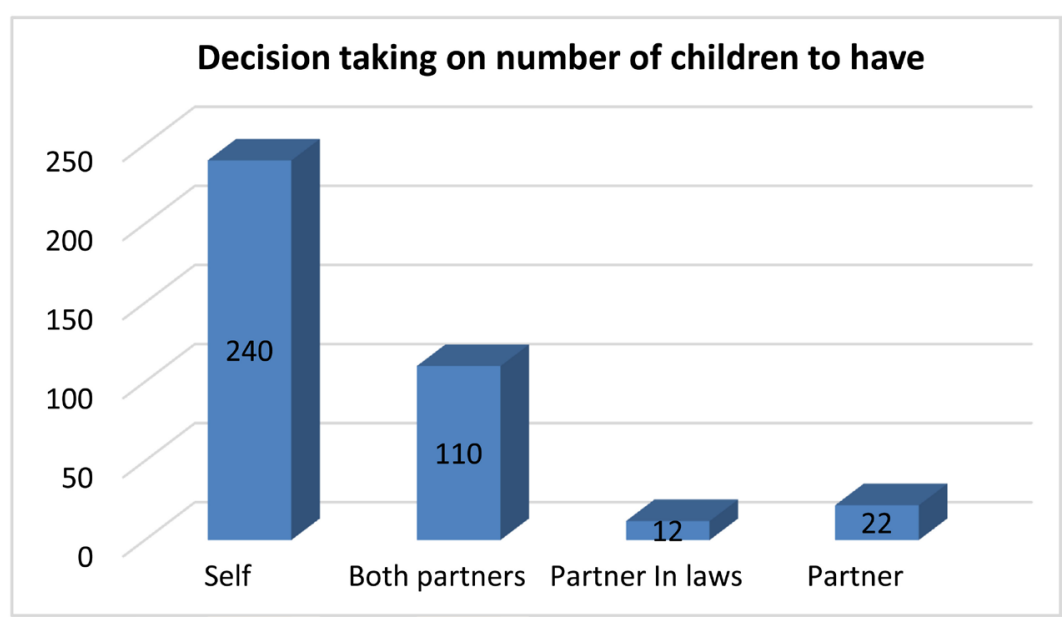

Figure 1. Discussion on the number of children to have.

\section{Discussion}

The study descriptively explores male's participation in family planning and 
willingness to support their partners or wives in family planning service uptake. Despite the high proportion of males who had had information about family planning, several misconceptions about family planning were demonstrated. The study found that males' involvement in Family Planning though marginally above average was comparatively moderately high compared to consistent pattern of low rates of male involvement in Family Planning practice [11].

Although all men could name at least one family planning method, few understood how this particular method worked. Some expressed ambivalence about what constitutes "safe days" in the context of periodic abstinence, an indication of little or no concrete education on family planning in the study setting The findings of the research indicate that study participants were in the position to support their wives to practice family planning but few men wanted to be the persons responsible to receive any Family Planning medication or package. Nevertheless, child spacing is not much prioritized and valued by not more than half of the people. There seems to be a declining trend in terms of preference for large family size at the industrial centre as it is in other parts of Sub-Sahara Africa where women in particular prize it [2] [6] [14] [15].

However Abstinence is the preferred means of assuring long birth intervals because of the traditional belief about contraceptive usage [16]. Furthermore, children as the cornerstone of marriage were seen as women's obligation. Males at the Suame light industrial area were in no position to pose a threat to their wives reproductive obligation. The threat of such abrogation of responsibility could causes problems in the home. As far as their wives were willing to give birth, the males would support them. These socio-cultural arguments were advance in favour of the existing preference for large family size. It is also very pertinent to note that religious barriers to family planning still persist as some respondents claim that the religious denomination forbids them to consider family planning practices in their marriages. Though this is not very significant in the study, it is very crucial for measures to be put in place to uproot these barriers to family planning.

The research brought to the fore that an overwhelming majority of the sample (90 percent) indicated that they have an appreciable knowledge of family planning. This is due to the activities family planning institutions and service providers and is clearly a reflection of the impact of aggressive campaigns and motivational efforts put in place by the family planning service providers. The major source of family planning information came from the mass media out of which $70 \%$ of information was through the radio. This corroborates [16] studies that men have radio as their major source of family planning information. Despite the general knowledge of family planning, current usage of contraceptive is very low of family planning (39\%) and only through condom use which was relatively high. This result in sharp contrast to works in India where condom use among males was very low and variations also existed among the males age cohorts [17]. 
The survey reveals that for the total number of males who made efforts to obtain a contraceptive method whether overtly or covertly (129), 53.9\% of males did not get a preferred family planning method of their choice. In the case of all other contraceptives which were mostly available for women, few male respondents had correct knowledge as to how the method is used. This suggests that a strategic approach to contraceptive utilization by men would have to be launched [18]. The focus therefore should be primarily on emphasizing existing male-dominated social institutions for health and family promotion and simultaneously advancing women's autonomy, so that women can be in position to pursue their personal preferences in matters of family planning.

Reviewed literally works and several studies have confirmed that the use of multiple channels of communication yields positive results for male involvement in family planning. Currently, fragmented services serve as an inconvenience to male clients. The training required is one of multi-purpose skilled health workers who will deliver integrated family Planning and sexual health services. Radio has been noted to be very effective. The result of this study shows that $2 / 3$ of the sample (70 percent) obtained information on family planning form the FM stations. This can serve as an effective means of reaching out to males. Moreover, field-workers including Community Health Officers, Public Health Nurses and Volunteers should approach men during working days to explain and answer questions about health and family planning services to erase the misconceptions.

Frequently, family planning sessions should be organized for the men in groups at the area. There is the need to encourage open discussion of family planning among male small groups. It is also interesting to admit that as long as only modern contraceptive methods are considered, male methods remained significantly low only $38 \%$ of males reported to have used any modern method of contraception male respondents. The proportion increases to about 67 percent, once all the methods including withdrawal and periodic abstinence are considered. This indicates that overall participation of men in family planning utilization was not as poor as generally believed though men participated in different forms in Family Planning practice. Despite the fact that men have ample knowledge about family planning usually distorted they want to be involved in family planning discussions and information sharing.

This is somewhat surprising and contradicts the general notion that men are not interested in family planning issues. The findings however are similar to those found among men in Khartoum, Sudan [6] where approval of family planning by men has been found to be relatively higher but with few modern contraceptive usages. This is also consistent with findings by Mwageni and others [14] in Tanzania, where most men interviewed expressed a positive attitude towards fertility regulating methods. It has been reported that, men from Zimbabwe were very amenable and receptive to a public campaign about family planning [10]. Again a quantitative study in Mpigi demonstrated that approximately $90 \%$ of married men were interested in gaining more knowledge about 
family planning [16].

All these works were consistent with this findings of which the only variation lied in the proportion of male contraceptive usage which the Suame industrial area had a very small percentage (39\%) but is relatively higher compared to reports from different Africa settings. What therefore remains is a conceptual detour in the objectives concerning male involvement in the family planning from increasing contraceptive use and achieving demographic goals to effective men participation in the family planning and reproductive health.

In Japan and other countries, some studies have reported that male methods have played a greater role in fertility control to support female methods. Efforts to promote family planning, in developing countries have therefore, been criticized for their exclusion of men and this has to be re-examined. From the survey the greater number of males who admitted the need for males to be involved in family planning $(56.2 \%)$ is eye opening and welcoming. This corroborates the position that programmes can serve family needs better when it addresses men as well as women [18]. The implication is evident in the difficulty family planning programmes has had achieving success due to failure to involve men.

\section{Conclusions}

The extent of active male involvement in family planning programmes has been identified to be extremely discouraging. According to the findings of the research, knowledge of family planning is high (90\%) but approval of the practice is very low. The finding of this study provides sound evidence supporting the view that there is a gap in family planning knowledge and actual practice. Relatedly, these findings highlight the need for non-clinic means of disseminating family planning information, services and supplies to improve use in the magazine industrial area. It is also important that policy makers use the mass media in creating awareness and motivation for family planning.

There is an urgent need for contraceptive advertising to contain more information on male family planning methods and facilities. Participation in local small based groups (welders association, straighter association, spare parts dealers association) will help build collaboration and establish open discussions on family planning and other health related issues. Community drama programmes should emphasize on "Responsible manhood" which can further lead to internalizing of the male involvement in family planning concept in the country.

The effectiveness of Family planning service utilization will be achieved if family planning service provision is designed whiles prioritizing the role religion and socio-cultural factors play in service uptake by males. When providers are men and they go and talk to fellow men about family planning, some way somehow they will respond. The socio-cultural stigma attached with males discussing family planning issues with female service providers or being attended to by female nurse would be eliminated significantly. On a contrary if a woman goes and talks to a man about family planning, men can feel threat- 
ened and intimidated and do not respond. Additionally, family planning providers should focus on counseling couples together. This may alleviate some of the distrust associated with a woman approaching her husband to begin practicing family planning.

\section{Limitation of the Study}

This study is limited by the fact that the analytical technique is purely descriptive and does not provide much insight in drawing causal inference. However, the descriptive approach adopted by the authors is important in bringing to bear the nature of male involvement and men's perspective on their involvement as a whole. It provides the basis for further study that will aim at exploring the predictors of male involvement or non-involvement.

\section{Acknowledgements}

The authors would like to acknowledge all the men who availed themselves as study participants.

\section{Funding}

This research did not receive any specific grant from funding agencies in the public, commercial, or not-for-profit sector.

\section{Availability of Data and Materials}

The dataset(s) supporting the conclusions of this article have been included within the article.

\section{Author's Contributions}

SCYA, POS PAL and FAO designed and carried out the study. POS and AGT contributed substantially to the design of the study. FAO, NKM assisted in the design and analysis. SCYA wrote the first draft which was critically reviewed by the three. All authors read and approved the final manuscript.

\section{Conflicts of Interest}

The authors declare no conflicts of interest regarding the publication of this paper.

\section{References}

[1] Das, B. and Tarai, D. (2011) Decision-Making and Fertility Behaviour: A Comparative Analysis of Scheduled Caste and Scheduled Tribe Women in Odisha. Social Change, 41, 233-249. https://doi.org/10.1177/004908571104100203

[2] Hawkins, K. (1992) Male Participation in Family Planning: A Review of Programme Approaches in Africa. International Planned Parenthood Federation, London.

[3] WHO (2001) Programming for Male Involvement in Reproductive Health.

[4] Fortier, L. (2013) Cultural Barriers to Family Planning. Girls' Globe. 
[5] Hussain, N.A., Akande, T.M., Osagbemi, G.K., Olasupo, S.T., Salawu, K.Y. and Adebayo, E.T. (2013) Perception and Practice of Contraception among Male Soldiers in Sobi Barracks, Ilorin, Nigeria. African Health Sciences, 13, 415-422. https://doi.org/10.4314/ahs.v13i2.31

[6] Khalifa, M.A. (1988) Attitudes of Urban Sudanese Men toward Family Planning. Studies in Family Planning, 19, 236-243. https://doi.org/10.2307/1966555

[7] UNFPA (2004) UNFPA Annual Report 2004. UNFPA-United Nations Population Fund. http://www.unfpa.org/publications/unfpa-annual-report-2004

[8] Bietsch, K.E. (2015) Men's Attitudes towards Contraception in Sub-Saharan Africa. African Journal of Reproductive Health, 19, 41-54.

[9] Touré, L. (2013) Male Involvement in Family Planning a Review of Selected Program Initiatives in Africa.

[10] Piotrow, P.T., Kincaid, D.L., Hindin, M.J., Lettenmaier, C.L., Kuseka, I., Silberman, T., Zinanga, A., Chikara, F., Adamchak, D.J., Mbizvo, M.T. and Lynn, W. (1992) Changing Men's Attitudes and Behavior: The Zimbabwe Male Motivation Project. Studies in Family Planning, 23, 365-375. https://doi.org/10.2307/1966894

[11] Wiafe, E. (2015) Male Involvement in Family Planning in the Sunyani Municipality. MPH Dissertation, University of Ghana, Ghana, Accra.

[12] Aviisah, P.A., Dery, S., Atsu, B.K., Yawson, A., Alotaibi, R.M., Rezk, H.R. and Guure, C. (2018) Modern Contraceptive Use among Women of Reproductive Age in Ghana: Analysis of the 2003-2014 Ghana Demographic and Health Surveys. BMC women's Health, 18, 141. https://doi.org/10.1186/s12905-018-0634-9

[13] Frimpong, E.D. (2008) Welcom to Kumasi, The Garden City of Africa: Suame Magazine Makes Breakthrough.

http://enochdarfahfrimpong.blogspot.com/2009/02/suame-magazine-makes-breakt hrough.html

[14] Mwageni, E.A., Ankomah, A. and Powell, R.A. (2001) Sex Preference and Contraceptive Behaviour among Men in Mbeya Region, Tanzania. BMJ Sexual \& Reproductive Health, 27, 85-89. https://doi.org/10.1783/147118901101195317

[15] Ringheim, K. (1996) Male Involvement and Contraceptive Methods for Men: Present and Future. Social Change, 26, 88-99.

[16] Kaida, A., Kipp, W., Hessel, P. and Konde-Lule, J. (2005) Male Participation in Family Planning: Results from a Qualitative Study in Mpigi District, Uganda. Journal of Biosocial Science, 37, 269-286. https://doi.org/10.1017/S0021932004007035

[17] Khan, M.E. and Patel, B.C. (1997) Reproductive Behaviour of Muslims in Uttar Pradesh. Journal of Family Welfare, 43, 13-29.

[18] Nazzar, A., Adongo, P.B., Binka, F.N., Phillips, J.F. and Debpuur, C. (1995) Developing a Culturally Appropriate Family Planning Program for the Navrongo Experiment. Studies in Family Planning, 26, 307-324. https://doi.org/10.2307/2138097 